\title{
Bio-Based Paths to Prosperity for Small and Medium Forest Landowners: A Pilot Study in Southwest Louisiana
}

\author{
Roger Smithhart ${ }^{1}$, Richard P. Vlosky ${ }^{1}$, Michael Blazier ${ }^{2}$, Paul Darby ${ }^{3}$, \\ Glenn Hughes ${ }^{4}$, Dek Terrell ${ }^{5}$ \\ ${ }^{1}$ Louisiana Forest Products Development Center, Louisiana State University Agricultural Center, \\ Baton Rouge, USA \\ ${ }^{2}$ Hill Farm Research Station, Louisiana State University Agricultural Center, Baton Rouge, USA \\ ${ }^{3}$ Department of Agricultural Economics and Agribusiness, Louisiana State University Agricultural Center, \\ Baton Rouge, USA \\ ${ }^{4}$ Forestry Extension, Mississippi State University, Starkville, USA \\ ${ }^{5}$ Economics Department, Louisiana State University, Baton Rouge, USA \\ Email: rvlosky@agcenter.lsu.edu
}

Received June $14^{\text {th }}$, 2012; Revised July $23^{\text {rd }}$, 2012; Accepted August $9^{\text {th }}, 2012$

\begin{abstract}
Forest biomass has great potential as a biofuel feedstock, but information on forest owner perceptions of using forest biomass to produce bioenergy is lacking. In this case study, we surveyed 3500 small to medium private forest landowners in southwestern Louisiana to better understand their attitudes and perceptions towards harvesting forest biomass for bioenergy production. Results indicate that landowners: 1) were positive about utilizing biomass for bioenergy, 2) believe viable biomass conversion technologies exist, 3) had antagonistic or neutral attitudes towards some technological, economic, and policy issues associated with using forest biomass for bioenergy due in part to lack of information or knowledge, and 4) felt biomass is a low-value product compared to traditional products. Landowners' perceptions of participating in bio-based activities and markets vary among age and ownership size, and $51 \%$ of forest landowners were willing to participate in management activities specifically geared for bioenergy production.
\end{abstract}

Keywords: Small \& Medium Non-Industrial Forest Landowners; Biomass; Business Potential; Louisiana

\section{Introduction}

In recent years, policymakers, legislators, developers, and energy producers in the United States have been searching for economically viable renewable domestic energy sources. Hydro-electric, geothermal, wind, solar, and biomass energy are the most common forms of renewable energy sources that are being used to alleviate our dependency on fossil fuels. Biomass is an attractive choice because it is cost-efficient, clean, and currently the only renewable source of liquid transportation fuel (Perlack et al., 2005; USDOE, 2010; USDA, 2009).

Biomass energy comes from biological resources such as agricultural crop residues, fuelwood, charcoal, animal and municipal wastes or other biofuels derived from plant material. Currently in the US, biomass provides about seven percent of the total energy consumption, supplying 7.3 quads BTU (EIA, 2009). Wood plays an integral role in the biomass energy group by providing approximately a third of the renewable energy consumed, or 2 quads BTU in the emerging bio-based markets (EIA, 2009).

There are several government policy issues associated with bioenergy in the United States. Government intervention in energy markets has a long history in the United States, with some of the earliest efforts dating to World War I policies for stimulating oil and gas production. Today, there are numerous subsidies provided to the energy industry. Direct subsidies to the industry include direct payments to producers and consumers and tax credits for certain activities such as drilling coalbed methane wells. Indirect subsidies consist of government finan- cial commitments that affect consumption and production costs, such as loans or loan guaranties, insurance services, tax exempt interest on debt, and research and development (EIA, 1992). Some of these types of subsidies have been recently created for the renewable fuels market as well. Specific programs geared towards assisting growers (landowners) are the Woody Biomass Utilization Grants and the Biomass Crop Assistance Program funded by the USDA (Perlack et al., 2005; USDA, 2010). These programs were designed to aid in the supply of biomass to the market by providing grants addressing the national challenge of utilizing low-value forest products and by providing financing to help farmers integrate energy feedstock production into existing cropland (USDA, 2010). Government mandates and policy incentives may promote bioenergy demand, which would create the need for a sustainable supply.

The US South is an area rich in natural resources, accounting for approximately $40 \%$ of the total forest lands in US and producing about $55 \%$ of the total annual round wood harvest (Prestemon \& Abt, 2002). Of the 200 million acres of timberlands in the South, approximately $90 \%$ (181 million acres) are privately owned either by forest industry or non-industrial private forest landowners (NIPF) (Conner, 2002). Understanding the characteristics of these producers should have positive economic impacts for individuals, families, and communities within their regions. A large portion of research within the forest industry sector over the past few decades has revolved around NIPF, which is synonymous with the current term family forest owners. Justification of such inquiries is partially 
attributed to the relative size of forestland owned by this group. From 1993-2003, this group increased by $11 \%$, and studies indicate this trend persists (Butler \& Leatherberry 2004; Hodgden et al., 2003). Despite NIPF land ownership increases, the average area of individual land ownership has decreased due to fragmentation. According to the USDA (2010), the majority of private forestlands are less than a thousand acres.

While consistencies appear among landowner characteristics (e.g. age, income, education, ownership size), landowner motivations for ownership and management objectives indicate a range of diversification, as suggested by the annotated review of Hodgen et al. (2003). Atop the list of reasons identified for owning forestland include asset for heirs, part of residence, recreation/personal enjoyment, and aesthetics while timber production remains relatively low (Butler \& Leatherberry, 2004; Hodgden, 2003; Measells et al., 2005). However, studies done in Louisiana indicate timber production to be the main reason for owning forestland (Perera, 2008; Vlosky, 2000). Recent studies have also shown that NIPF landowners have a low knowledge level of biomass harvesting, production, policies, and economics (Almquist, 2006; Oxarart, 2008; Shaw, 2009). Motivations for management objectives and harvest intensities also vary among determinant factors such as size of ownership, length of ownership, presence of structures and absenteeism (Conway et al., 2003; Hodgden, 2003; Perera, 2008).

Given the potential of the South US to provide forest biomass as biofuel feedstocks and its land ownership patterns, it is imperative to understand small and medium landowner willingness to participate in bio-based product management activities. With the guidance of the previously mentioned research, we hypothesized that landowners would be willing to participate in such activities. The objectives of the study was 1) to develop a baseline understanding of the role that current forest products play in the supply chains from producers to consumers within the focal region, 2) to identify prerequisites and willingness to shift existing production to potentially higher value biobased alternatives, and 3) to discern the willingness to plant bio-based forest species dedicated to producing bio-based products.

\section{Study Context}

Louisiana, the study region, is typical of southern states, with NIPF landowners accounting for about $62 \%$ ownership of the 13.8 million acres of forestland (LSU AgCenter, 2009). Louisiana is rich in renewable natural resources readily available for bioenergy production from the forestry industry. Approximately 4289 million kwh 1 (5.43 gigajoules) of energy can potentially be produced from woody biomass residue in Louisiana (de Hoop, 2006).

The purpose of this research was to survey small and medium private forest landowners (SMAPFLs) in the US Gulf South using Louisiana as a pilot state in order to identify current and potential business positions as well as identify willingness to participate in new cellulosic bio-based management activities. Small forest landowners are defined as those having between 10-139 acres and medium producers as those having 140-999 acres (USDA, 2009). The survey encompassed a five-parish region in Southwest Louisiana (Vernon, Rapides, Beauregard, Allen, and Calcasieu) which has considerable forest resources but a relatively low intensity of forest utilization (Figure 1). The study region chosen has characteristics similar to the land base in the Gulf South. Intentions were to develop methods that could be utilized throughout most of the US South.

\section{Survey Methods}

The survey portion of this research was focused on developing qualitative and quantitative information on the forestry sector. It was a survey of 3500 small to medium forest landowners with forest ownership within the focal region chosen by random sample from tax roll data. Information gained from the survey was further analyzed to characterize the populations and regions as well as given rating scale data to aid in managerial decision making. This understanding and knowledge ensures landowners have access to all current and emerging markets in order to make informed decisions regarding participation in cellulosic biomass-based business endeavors.

The primary target of preliminary research for developing the survey was scientific journals and periodicals. However, other professional publications of relevance were chosen with consultation. The survey for forest landowners had four sections containing questions involving issues relevant to ownership, biomass knowledge, biomass market and policy implications, and socio-demographics. All surveys contained a cover letter with information about biomass, the survey, and a return envelope. Survey procedures, follow up efforts, and data analysis were conducted in accordance with Tailored Design Method (Dillman, 2000).

\section{Results}

\section{Response Rate, Respondent Demographics, and Profile}

Of the 3500 surveys mailed, 449 were either undeliverable, inappropriate due to respondent being deceased, non-forest landowner, or unwilling to participate in the survey. There were a total of 162 unusable surveys and 942 usable surveys, for an overall adjusted response rate of $28.2 \%$. T-test statistics were used to compare continuous variables, and chi square tests were used to compare categorical data between first and second mailing in order to investigate non-response bias. Approximately $93 \%$ of the questions were not significantly different; therefore, the research results can be considered a fair representation of the sample frame.

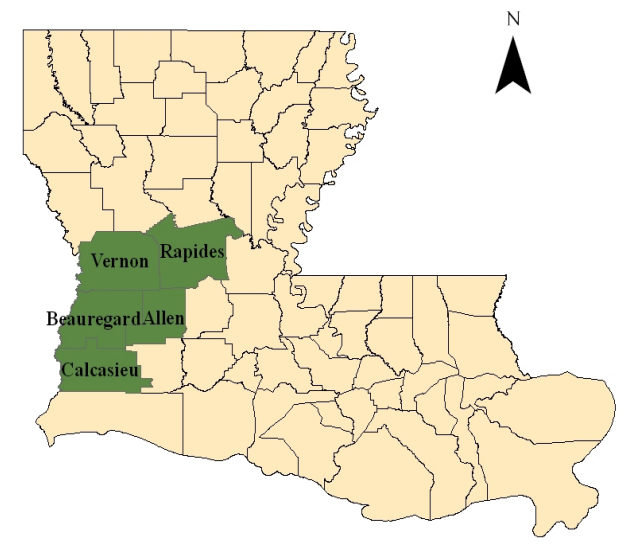

Figure 1.

Study region. 


\section{R. SMITHHART ET AL.}

Over $76 \%$ of the respondents were males $(n=679)$, and approximately $73 \%$ were 55 years or older $(n=663)$. A little over $52 \%$ earned a college degree $(n=679)$, and the largest percentage $(19 \%)$ were in the highest income category (over $\$ 150,000)$. Approximately $80 \%$ of the respondents resided in the state of Louisiana where they owned forestland $(n=726)$. The general tendency of these SMAPFLs was to acquire land rather than to dispose or sell their forest lands. Over $63 \%$ of the respondents owned less than 80 acres of land $(n=798)$ (Figure 2). The majority of respondents $(85 \%)$ chose the individual ownership category $(\mathrm{n}=784)$.

\section{Biomass Perceptions and the Impetus for Policy and Markets}

Questions were asked to discover landowners' knowledge and perceptions on biomass concepts and utilization (Table 1). The majority of the responses from the questions either had the highest chosen value as "neutral" or was heavily clustered around neutral. The high numbers of neutral responses coupled with a majority of responses not in the appropriate direction indicate landowners' uncertainty toward the state of technological advancements in the conversion of wood biomass to bioenergy. Such responses could also indicate a general lack of knowledge landowners have on the emerging bio-based markets.

Slightly over $63 \%$ of respondents have positive attitudes of using biomass for bioenergy $(n=915)$ while $82 \%$ agree that we should use residual wood waste from forest harvesting activities for bioenergy production $(\mathrm{n}=900)$. Almost $50 \%$ of respondents would supply wood biomass to bio-refineries capable of producing energy for local $(n=899)$ and state $(n=900)$ needs while $45 \%$ would supply wood biomass for national energy needs $(\mathrm{n}=898)$. Despite the perceived affinity for biomass, only $43 \%$ of respondents agree that a bioenergy market will be competitive compared to conventional energy markets $(n=$ 903). The mean level of agreement for the statements "Residual wood waste from forest harvesting activities should be used for bioenergy production" and "a bioenergy market will be competitive compared to the conventional energy market" on a 5 point scale are 4.2 and 3.3 , respectively.

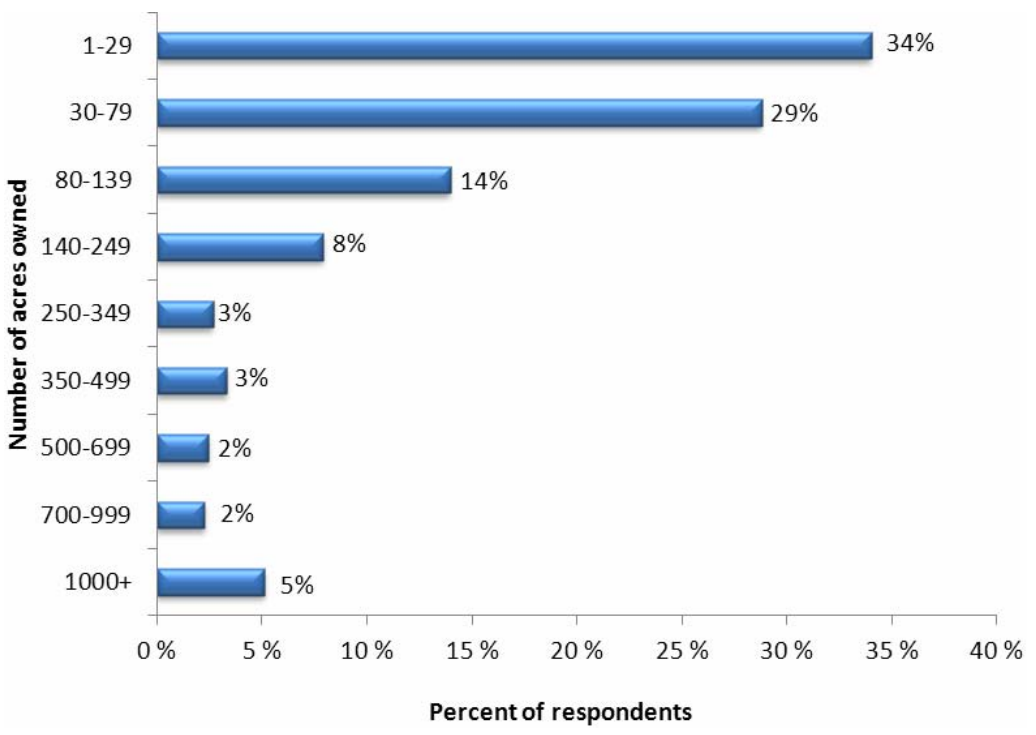

Figure 2.

Number of acres owned by percent of respondents in region, $\mathrm{n}=789$.

Table 1.

Landowner knowledge of key biomass concepts.

\begin{tabular}{|c|c|c|c|c|c|}
\hline Survey Questions & $\begin{array}{l}\text { Strongly } \\
\text { Disagree }\end{array}$ & $\begin{array}{l}\text { Somewhat } \\
\text { Disagree }\end{array}$ & Neutral & $\begin{array}{l}\text { Somewhat } \\
\text { Agree }\end{array}$ & Strongly Agree \\
\hline $\begin{array}{l}\text { Economically viable technologies exist for converting } \\
\text { biomass to bioenergy. }\end{array}$ & $4 \%$ & $10 \%$ & $30 \%$ & $38 \%$ & $18 \%$ \\
\hline $\begin{array}{l}\text { Agricultural biomass harvesting and collection will not } \\
\text { require extra personnel and equipment. }\end{array}$ & $13 \%$ & $30 \%$ & $32 \%$ & $18 \%$ & $6 \%$ \\
\hline $\begin{array}{l}\text { Agricultural biomass transportation can be done with } \\
\text { traditional agricultural equipment. }\end{array}$ & $6 \%$ & $14 \%$ & $34 \%$ & $36 \%$ & $11 \%$ \\
\hline $\begin{array}{l}\text { Converting agricultural biomass to bioenergy is a simple } \\
\text { process that can be done at most agricultural processing } \\
\text { facilities. }\end{array}$ & $5 \%$ & $17 \%$ & $40 \%$ & $28 \%$ & $11 \%$ \\
\hline $\begin{array}{l}\text { Agricultural biomass requires utilizing entire crop as well } \\
\text { as residual feedstock. }\end{array}$ & $7 \%$ & $19 \%$ & $40 \%$ & $27 \%$ & $8 \%$ \\
\hline
\end{tabular}


Just over $40 \%$ of respondents agree that harvesting biomass negatively impacts wildlife habitat $(\mathrm{n}=912)$. Almost $40 \%$ disagree that harvesting negatively impacts both air and water quality $(n=909)$ and soil quality $(n=908)$ while over $47 \%$ disagree that it will reduce growth production on standing timber $(n=899)$. Looking at market and policy issues, approximately $60 \%$ of the respondents agree that tax credits should be given to landowners, biomass harvesters, and companies that utilize biomass intended for energy production $(n=904)$. Around $41 \%$ of respondents agree government subsidies should be provided to companies for selling biomass $(n=901)$ while almost $45 \%$ agree that incentive programs should be provided to supplement costs of establishing biomass tree species $(n=$ 901 ). Over $62 \%$ of respondents agree that grants should be awarded for research and development capable of advancing biomass production technologies $(n=905)$.

Other statistical tests were used to see if demographics are related to key respondent perceptions. Respondents' ages were significantly related to beliefs that harvesting wood biomass negatively impacts wildlife habitat, air and water quality, and soil quality (Table 2). Also, the size of ownership had a statistically significant relationship with the environmental impacts of harvesting biomass. The positive direction of the $\rho$ (rho) value suggests that as respondents' age increases so does their belief that harvesting biomass negatively impacts the environment. In contrast, the negative direction of the $\rho$ (rho) value suggests that as the amount of acres owned by respondents increases so does their tendency to disagree that harvesting biomass negatively impacts the environment. This should be an important note for energy producers, entrepreneurs, and policy makers as this study as well as previous research suggests the majority of private landowners are older individuals with relatively small parcels of land. All items compared to respondent age in Table 2 are highly significant except the belief that harvesting wood biomass will reduce growth production on standing timber $(\rho($ rho $=0.065)$.

Concerning market and policy issues, respondents' ages were significantly related with whether or not respondents believe tax credit or government programs should be provided for biomass establishment, selling, and utilization (Table 3). The size of ownership showed a significant relationship with whether or not respondents believe tax credit or government programs should be provided for biomass establishment, selling, and utilization. The negative direction of the $\rho$ (rho) values suggests that as age increases so does respondent's tendency to disagree that government programs or incentives should be provided for the utilization, selling or establishing biomass. The positive direction of the $\rho$ (rho) values suggests that as ownership size increases so does respondent's tendency to agree that government programs or incentives should be provided for the utilization, selling or establishing biomass. This is another important note for energy producers, entrepreneurs, and policy makers as research suggests the majority of private landowners are older individuals with relatively small parcels of land.

Table 2.

|NIPF landowners perceptions of environmental issues and socio-demographics.

\begin{tabular}{|c|c|c|c|c|c|c|}
\hline \multirow[b]{2}{*}{ Biomass Issues } & \multicolumn{3}{|c|}{ Age } & \multicolumn{3}{|c|}{ Acres Owned } \\
\hline & $\mathrm{n}$ & $\rho$ (rho) & $p$-value & $\mathrm{n}$ & $\rho($ rho $)$ & $p$-value \\
\hline $\begin{array}{l}\text { I believe harvesting wood biomass negatively impacts } \\
\text { wildlife habitat }\end{array}$ & 884 & 0.126 & 0.000 & 884 & -0.175 & 0.000 \\
\hline $\begin{array}{l}\text { I believe harvesting wood biomass negatively impacts air } \\
\text { and water quality }\end{array}$ & 909 & 0.115 & 0.000 & 909 & -0.237 & 0.000 \\
\hline $\begin{array}{l}\text { I believe harvesting wood biomass negatively impacts } \\
\text { soil quality }\end{array}$ & 908 & 0.092 & 0.000 & 908 & -0.245 & 0.000 \\
\hline $\begin{array}{l}\text { I believe harvesting wood biomass will reduce growth } \\
\text { production on standing timber }\end{array}$ & 873 & 0.051 & 0.065 & 896 & -0.165 & 0.000 \\
\hline
\end{tabular}

Table 3.

NIPF landowner perceptions of biomass markets/policies issue and socio-demographics.

\begin{tabular}{|c|c|c|c|c|c|c|}
\hline \multirow[b]{2}{*}{ Biomass Issues } & \multicolumn{3}{|c|}{ Age } & \multicolumn{3}{|c|}{ Acres Owned } \\
\hline & $\mathrm{n}$ & $\rho($ rho $)$ & $p$-value & $\mathrm{n}$ & $\rho($ rho $)$ & $p$-value \\
\hline $\begin{array}{l}\text { Tax credits should be given to landowners, harvesters, and } \\
\text { companies that utilize biomass for bioenergy }\end{array}$ & 904 & -0.142 & 0 & 896 & 0.382 & 0.01 \\
\hline $\begin{array}{l}\text { Subsidies should be provided as an incentive to companies } \\
\text { for selling biomass residues from forestry and mill opera- } \\
\text { tions }\end{array}$ & 901 & -0.104 & 0.002 & 898 & 0.443 & 0.005 \\
\hline $\begin{array}{l}\text { Incentive programs should be provided to supplement the } \\
\text { costs of establishing biomass tree crop species }\end{array}$ & 901 & -0.147 & 0 & 898 & 0.156 & 0.034 \\
\hline
\end{tabular}


Other concerns included the motivations for the forest community to be involved in bio-based markets. When asked what prerequisites would it take for respondents to participate in a biomass to bioenergy market, $21 \%$ choose "profit", $20 \%$ chose "doesn't harm wildlife habitat", $20 \%$ chose "doesn't cause erosion", $18 \%$ chose "doesn't deplete the soil of nutrients", $15 \%$ chose "knowledge and training", $4 \%$ chose "it might upset existing sectors that use the same raw materials (e.g. chips for pulp/paper), and $2 \%$ chose "other" $(\mathrm{n}=942)$. The top comments suggested in the "other" option for participating included "professional services provided", "ensure sustainability and reforestation", "cooperative workshops provided", and "must help local markets".

\section{Management Issues}

Approximately $66 \%$ of the forest landowners reported they harvested trees from their property during the span of their ownership. The top three products harvested were fuelwood for personal use (32\%), pulpwood for sale $(28 \%)$, and sawlogs for sale $(26 \%)(n=941)$ (Figure 3). Out of 410 respondents, $71 \%$ plan to harvest trees for their personal use from their land within ten years or in the distant future.

Out of 780 respondents, $89 \%$ plan to harvest trees for sale from their land within ten years or in the distant future. Approximately $88 \%$ of respondents did not have a written forestry plan and $12 \%$ did $(n=687)$. A little over $64 \%$ of respondents with written forestry plans claimed someone else prepared the plan. Foresters or forestry professionals were the highest re- sponse given when asked who prepared the plan.

Respondents were asked about their perceptions of current management activities as well as management of biomass for bio-based products. Over $77 \%$ of the respondents believe they practice sustainable forestry $(\mathrm{n}=895)$. When asked about specific activities, a little over $80 \%$ did not use herbicide treatments $(\mathrm{n}=908)$ and almost $72 \%$ did not use prescribed burns $(n=910)$. Over $74 \%$ of the respondents say that none of their management costs involve burning or removing slash piles or harvesting residues from harvesting activities $(n=901)$. Over $52 \%$ of respondents either somewhat or strongly agree that wood biomass harvesting will help diversify the management activities of their timberland $(n=896)$.

Approximately $51 \%$ of the respondents would be willing to participate in managements activities specifically geared toward biomass production (e.g. short rotation woody crops) $(n=874)$. Overall, $62 \%$ of respondents had a positive perspective regarding using biomass for bioenergy (Figure 4).

Using the Pearson chi square test, forest type was significantly related to willingness to plant short-rotation woody crops (chi2 $=30.257, p=0.000, \mathrm{n}=874$ ). The forest types included natural hardwoods, natural pines, mixed hardwoods and pine, planted hardwood, planted pines, and other. The majority of respondents $(55 \%)$ owned mixed hardwoods with the second highest forest type being planted pines $(16 \%)(n=941)$. The willingness of landowners to participate in biomass management activities was rather evenly distributed across all categories except for two in particular. A little more than half of the

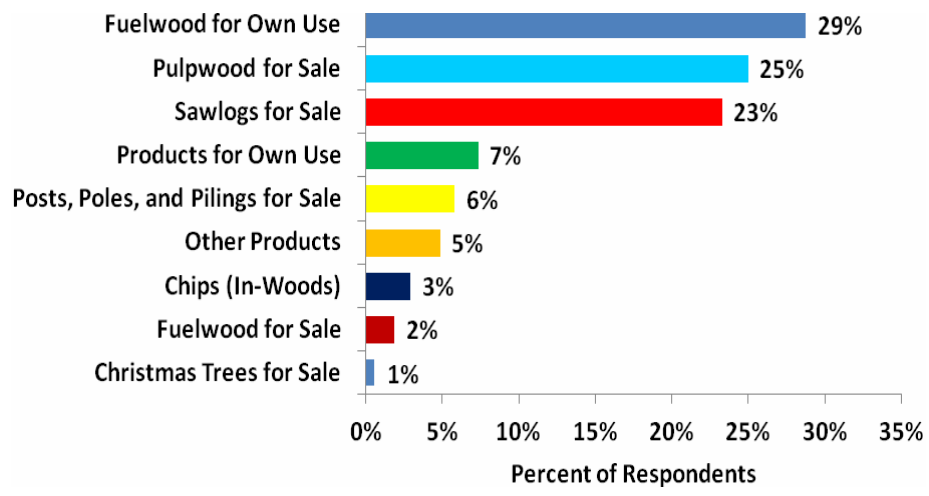

Figure 3.

Respondents' product utilization from harvested trees, $\mathrm{n}=941$.

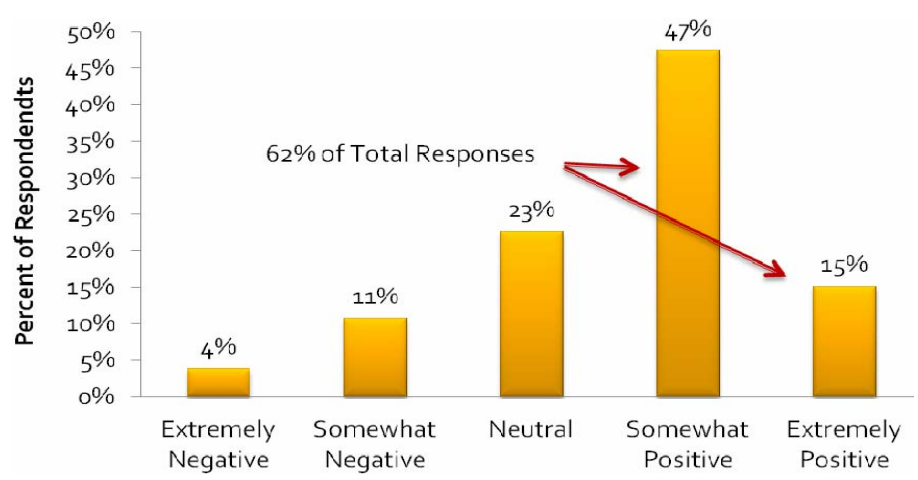

Figure 4.

Percentage of NIPF landowner answering "What is your overall opinion of using biomass for bioenergy?" $(\mathrm{n}=924)$. 
respondents with natural hardwoods answered "no" as opposed to those answering "yes". In contrast, more than half of the respondents with planted pine answered "yes" as opposed to those answering "no" when asked to participate in biomass management activities. This suggests that respondents already involved in intensive management activities (i.e. planting pines) are more willing to participate in planting dedicated biomass energy crops.

\section{Conclusion}

Results indicate the majority of landowners believe that economically viable technologies exist for converting wood biomass to bioenergy. They also tend to believe that wood biomass harvesting and collection doesn't require extra personnel and equipment, can be transported with traditional equipment, and can be easily converted to bioenergy at most pulp/paper or saw mills. The high numbers of neutral responses could indicate landowners' ineptitude toward the state of technological advancements in the conversion of wood biomass to bioenergy. Such responses also underscore the insufficient amount of knowledge landowners have on the emerging bio-based markets. These individuals should be looked at as an ideal base for administering information as well as involving in future discussions from the forest industry.

In general, a rather large amount of landowners feel positive about using wood biomass for bioenergy. Despite their perceived affinity, only about half are willing to supply biomass feedstock or participate in bio-based activities and even less believed a bioenergy market will be comparatively competitive to conventional energy markets. Therefore, a clear gap exists between the desire to utilize wood biomass and the perceived viability of bio-based markets.

Results from this study indicate those landowners' perceptions of environmental, market, and policy issues were influenced by several socio-demographic variables. Results indicate that older landowners believe that harvesting biomass will negatively impact wildlife habitat, air, water, and soil quality. They also believe tax credits, subsidies, and incentive programs should not be provided for biomass establishment, selling, and utilization. In direct contrast, results shows that larger landowners do not believe that harvesting biomass will negatively impact wildlife habitat, air, water, and soil quality and do believe tax credits, subsidies, and incentive programs should be provided for biomass establishment, selling, and utilization. As mentioned earlier, most of the landowners surveyed were older individuals, with only a small percentage being medium to large landholders. This is an important note for policy makers, legislators, and local officials to take forward when creating policies intended to foster the development of bio-based markets.

Most forest landowners harvested trees from their property during their ownership, with two of the top products pulpwood and sawlogs. Also, the majority of landowners (89\%) plan to harvest trees for sale from their land within the next ten years or in the future. Despite the seemingly large amount of current and future production, a startling amount of landowners $(88 \%)$ do not have written forestry plans. This coincides with the fact that the majority of landowners in southwestern Louisiana did not use intensive management methods such as prescribed burns and herbicide treatments nor did the majority have any of their costs involve removing or burning slash and residue piles from harvesting activities. The long-term commitment of bio-based facilities will likely depend upon the availability of supply within the area. It is important to stay abreast of current and future forest production and subsequent products in order to realize the potential amount of biomass supply.

The majority of landowners either somewhat or strongly agreed that wood biomass harvesting will help diversify the management activities of their timberland. More exacting, a narrow majority of landowners $(51 \%)$ would be willing to participate in management activities specifically geared towards biomass production such as short rotation woody crops. When asked what it would take to participate, the majority report profit, with assurance that no harm will be done to the environment following close behind. Thus, there is an inherent need for landowners to be reassured of the profitability of bio-based products and that no harm will be done to the environment during their production. Additionally, the apparent scarcity of intensive management activities coupled with the lack of written forestry plans beckon the overall need for professional assistance. For those unconsciously managing their forests or unwilling to participate in biomass management activities, the invaluable services of educational programs should be provided in order to help diversify their portfolios and bolster rural economies.

\section{REFERENCES}

Almquist, B. (2006). Environmental group perspectives on woody biomass utilization related to hazardous fuels reduction. Eugene, OR: University of Oregon.

Butler, J. B., \& Leatherberry, C. E. (2004). America's family forest owners. Journal of Forestry, 102, 4-14.

Conner, R. C., \& Hartsell, A. J. (2002). Forest area and conditions. Southern forest resource assessment-Technical report (pp. 357402). Asheville, NC: U.S. Department of Agriculture, Forest Service, Southern Research Station.

Conway, M., Gregory, C., Amacher, S., Sullivan, J., \& Wear, D. (2003). Decisions nonindustrial forest landowners make: An empirical examination. Journal of Forest Economics, 9, 181-203. doi:10.1078/1104-6899-00034

de Hoop, C. (2006). Biomass energy resources in Louisiana. Baton Rouge: Louisiana Forest Products Development Center, LSU Agricultural Center.

Dillman, D. A. (2000). The tailored design method. New York, NJ: John Wiley \& Sons, Inc.

Energy Information Administration (1992). Federal energy subsidies: Direct and indirect interventions in energy markets. EIA Service Report SR/EMEU/92-02.

Energy Information Administration (2009). Annual energy review. US Department of Energy. URL (last checked 20 March 2012). http://www.eia.doe.gov/emeu/aer/overview.pdf

Hodgden, B., Cusack, C., \& Tyrrell, M. (2003). Literature review: An annotated bibliography on family forest owners. In Sustaining family forests initiative wingspread conference: Yale program on private forests, Racine, 6-8 October 2003.

LSU AgCenter (2009). 2008 Louisiana summary of agriculture and natural resources. Baton Rouge, LA: Louisiana State University Agricultural Center.

Measells, M. K., Stephen, C., Grado, H., Glenn, H., Michael, A., Dunn, J. I., \& Zielinske, B. (2005). Non-industrial private forest landowner characteristics and use of forestry services in four southern states: Results from a 2002-2003 mail survey. Southern Journal of Applied Forestry, 29, 194-199.

Oxarart, A. (2008). Exploring written communication techniques for complex natural resource issues. Gainsville, FL.

Perera, P. K. P. (2008). Non-industrial private forest landowners and 


\section{R. SMITHHART ET AL.}

US home center retailers' attitudes and perceptions of forest certification, the school of renewable natural resources. Baton Rouge: Louisiana State University and Agricultural and Mechanical College.

Perlack, R. D., Wright, L. L., Turhollow, A. F., Graham, R. L., Stokes, B. J., \& Erbach, D. C. (2005). Biomass as feedstock for a bioenergy and bioproducts industry: The technical feasibility of a billion-ton annual supply. US Department of Energy. doi:10.2172/885984

Prestemon, J. P., \& Abt, R. C. (2002). The southern timber market to 2040. Journal of Forestry, 100, 16-22.

Shaw, D. S. (2009). Landowners' knowledge, attitude, and aspirations towards woody biomass markets in north Carolina. Raleigh: North Carolina State University.

United States Department of Agriculture (USDA) (2009). Census of agriculture. United States Department of Agriculture.

USDA (2009). President Obama issues presidential directive to USDA to expand access to biofuels. URL (last checked 14 December 2010). oc.news@usda.gov.

USDA (2010). Biomass crop assistance program for FSA. URL (last checked 14 December 2010). http://www.apfo.usda.gov/FSA/webapp?area=home\&subject=ener\&t opic=bcap.

United States Department of Energy (USDOE) (2010). US department of energy: Energy efficiency and renewable energy.

Vlosky, R. P. (2000). Certification: Perceptions of non-industrial private forestland owners in Louisiana. Baton Rouge, LA: Louisiana State University Agricultural Center. 